\title{
Explaining epistemic injustice in medicine: \\ tightrope walking, double binds, paths of least resistance, \\ and the invisibility of power positions to those who occupy them
}

Garrath Williams*

\begin{abstract}
Person centered healthcare requires providers to appreciate the knowledge and perspectives of patients. Effective and appropriate care depends on such knowledge. Medical institutions can only function well when they acknowledge patients' own experiences. Yet a range of evidence shows that professionals and organisations often ignore patients' own knowledge about their condition and treatment. This article aims to explain why this epistemic injustice occurs and persists. (Epistemic: to do with knowledge. Justice, because professionals and organisations do wrong when they bypass or deny patients' own knowledge.) The explanation focuses on problems of power and accountability. Illness is a disempowering experience, partly for bodily and psychological reasons, partly because the ill person depends on others for help, partly because professionals and organisations are specially empowered in order that they may help. Occupying a lesser power position, patients often walk a tightrope between conflicting demands and may be caught in double binds: situations where every possibility for action risks bad outcomes. By contrast, professionals need not notice their greater power position and how this opens up paths of least resistance, whereby it is easy to ignore or belittle patients' knowledge. When it is hard for patients to voice their "complaints" (the details of their illness, their sense of being badly treated), accountability falters. Healthcare providers may see themselves as expert and responsible, even as they fail many persons they are meant to help.
\end{abstract}

\footnotetext{
* Many thanks to Havi Carel and Rachel Cooper for organising the workshop on patient knowledge and involvement in healthcare where I presented a first version of these ideas, and to my fellow participants. Additional thanks to Liz Ashford, Ruth Chadwick, Sam Fellowes, Morris Kaplan, Ian Kidd, Veronika Koller, Mairi Levitt, Michael Loughlin, Mari Mikkola, Onora O’Neill, Elena Semino, Kristin Voigt, Jenny Waine, Myfanwy Williams and Robert Williams.
} 


\section{Explaining epistemic injustice in medicine: \\ tightrope walking, double binds, paths of least resistance, and the invisibility of power positions to those who occupy them}

\begin{abstract}
...the helplessness, fear, exasperation, and rage which a double bind situation provokes in the patient, but which the [people who impose that double bind] may serenely and un-understandingly pass over. - Gregory Bateson et al (1) ${ }^{1}$
\end{abstract}

What is needed for a person-centred approach to healthcare? Minimally, patients' accounts of their own illness and treatment, and their experience of healthcare professionals and systems, must be taken seriously $(\mathrm{x})$. This chapter explores a major obstacle to the development of person-centred healthcare, a problem that many patients have faced: the feeling of being ignored, disbelieved or mistrusted by medical professionals.

\section{Epistemic injustice}

Miranda Fricker (2) coined the term 'epistemic injustice, ${ }^{2}$ while Havi Carel and Ian Kidd (3), (4) have insightfully applied it to the healthcare context. Epistemic - to do with knowledge, evidence and expertise. Injustice - because a grave wrong is done when we do not take seriously a person's special authority concerning his or her own body and experiences. As Carel and Kidd document, this is not an accidental or occasional feature

1 At 261. Bateson refers to the 'mother' in this quotation; I have inserted a more general phrase since, as he also mentions (263), medical institutions and professionals impose double binds too.

2 Although I will only allude to them here, three schools of thought stand in the background. 1. 'Standpoint epistemology,' where 'standpoint' refers not merely to a particular perspective or social location, but also to insights gained through struggles against oppressive power dynamics (e.g. (18)). 2. Michel Foucault's work on the interrelation of power and knowledge in modern organisations and societies (e.g. (19)). 3. The turn to social and normative issues in epistemology: since knowledge is won by human beings acting together, moral phenomena such as testimony, credibility, humility and trust are fundamental to everyday knowledge and science alike (e.g. (20), (21)).
Commented [GW1]: Insert reference for: Loughlin, Michael, Mathew Mercuri, Alexandra Pârvan, Samantha Marie Copeland, Mark Tonelli, and Stephen Buetow. 2018. "Treating Real People: Science and Humanity." Journal of Evaluation in Clinical Practice 24 (5): 919-29

trust are fundamental to everyday knowledge and science alike (e.g. (20), (21)). 
of modern medical practice, to be explained away on a 'few bad apples' theory. Rather, it appears to be a systematic problem, attested to by patients from all walks of life and with an enormous variety of conditions. ${ }^{3}$ At the same time, it is not a conspiracy. If the medical profession sometimes appears to conspire against the laity, we should be able to explain this in structural terms - not by reference to widespread character flaws ('many bad apples'), but in terms of the pressures, constraints and obligations that face institutions and role-holders, so that individual competence and good will do not translate into responsible practice as often or as smoothly as they ought. ${ }^{4}$

Fricker distinguishes two overarching ways in which knowledge might be wrongly obscured. 'Testimonial injustice' refers to failures to listen or believe or heed. 'Hermeneutical injustice' refers to situations where a person or group lacks the resources to articulate their experiences - for example, as might happen to lay people faced with specialist jargon. Carel and Kidd delineate many ways these arise in medical contexts. The undoubted importance of medical expertise, and its complexity; the imperatives of large organisations; prejudices against ill persons (for example, as emotional or liable to give irrelevant testimony) - such factors mean that patients' experiences and judgments often take second place.

This chapter aims to complement Carel and Kidd's work by explaining in greater depth how gulfs in perspective can be maintained and remain hidden from well-intentioned professionals or - when those gaps are intuited - be accounted for in ways that discredit patients' views. It underlines not just why things go wrong, but also how our normal remedy for moral injuries is also impaired. Attempts to hold people and institutions responsible falter by virtue of the self-same epistemic problems: complaints about epistemic injustice are difficult to articulate and to make, and just as difficult to heed. Worse, blame and other penalties can actually move in the wrong direction - that is, against patients who try to bring their knowledge and experience to bear. To redress these

3 I will only cite a small selection of the relevant evidence; (3) (4) give more extensive references; see also (70) (22). Epistemic questions are central to many papers by Kirsti Malterud (e.g. (23) (71) (24)). In addition to references cited below, I have also learned from (25), (26), (27), (28).

4 The 'bad apples' question is mirrored by a debate in the literature on epistemic injustice: how far does it relate to individual vices and biases, or to broader features of social relations? (Cf (29): 2f.) Fricker's own work tends to emphasise the former, which I will highlight here as difficulties of practical wisdom. At the same time, I follow Anderson (72) and Bohman (73) in emphasising questions of organisation and power. Justice may name a virtue, but it is primarily a feature of social structures. 
dynamics requires painstaking measures to give a voice to the disempowered. To take such pains, we must appreciate both their difficulty and their necessity. Which is also to say: this chapter will focus on diagnosis and explanation, postponing the challenges of prescription and treatment.

My discussion will also simplify by focusing on one main, very general, vulnerability to epistemic injustice: where a person suffers in ways that pose difficulties for diagnosis or handling or treatment. ${ }^{5}$ In its most awe-inspiring form, the power of medicine is the power to cure. For many reasons, this power often fails. I will stress cases where a condition is chronic (simple remedy is unavailable; knowledge of how to manage the condition - and therapies - gains special weight), or where injury or symptoms or side-effects are unusual (evidently making diagnosis harder) or poorly understood (available diagnostic categories are contestable or inadequate, and in any case, do not point to satisfactory remedies). Another serious source of difficulty arises where a patient's concerns relate to her experience of medical services. These are not problems of diagnosis or treatment, as such, but rather of accountability and organizational learning. In all these cases, patients have privileged access to some forms of knowledge, concerning their own bodies and symptoms and experiences. ${ }^{6}$ Likewise, this knowledge takes on obvious importance in improving the care so far provided and helping the patient in whatever ways may still be possible.

My long subtitle indicates the simple structure that I will use to explore these complex issues. First, I point out that the role of patient is already a demanding one. The ill person finds herself ${ }^{7}$ walking a sort of ethical tightrope, negotiating moral and practical demands

5 There are many further, more specific sources of vulnerability to epistemic injustice in medicine recent investigations include: childhood (74), pregnancy (30), mental disabilities (75) or psychiatric diagnosis (76), (31), (77)). Conditions that are stigmatising or considered shameful also create difficulties, especially if some aspects of diagnosis or treatment are problematic - e.g. (32) (85).

6 In various places I will draw attention to ways in which language operates against patients. As many have noted, all the forms of knowledge just mentioned may figure as 'complaints' - already suggesting a 'hermeneutical' prejudice.

7 Three notes on terminology: 1. Throughout I use female pronouns to refer to patients. Obviously this resonates with power inequalities between the sexes, in ways that overlap with the power differential between patients and professionals. While this is useful to my argument, I should also disavow the unfortunate resonances with prejudices about female passivity. 2. For similar reasons, and with a similar caveat, I speak throughout of 'patients.' 3. I will often speak of medical professionals. This term is sometimes contested insofar as it marginalises nursing and allied health professions, and reinforces the power position of doctors, physicians and consultants. I use the term 
that are hard to combine. This happens when she is experiencing a condition - illness that is liable to throw a person off balance in so many ways. Sometimes, I suggest, it becomes impossible for the sick person to meet these competing demands. She thus finds herself caught in double binds - situations where, as we say, she 'can't do right for doing wrong.' This is often true at the social level, but my special concern is with interactions with healthcare professionals and services. Of course, those people and structures often work as they are meant to, using their power to assist those who are ill. But there is also good evidence that they are sometimes less helpful than they might be, and even damaging to patients. To explain this, I point out some paths of least resistance that medical professionals may take. Without appreciating that they are doing so, they can disadvantage the persons they are meant to help. These paths of least resistance open up because professionals occupy, not just positions of responsibility, but also power positions. But power is often invisible to its owner. Since power is lent by the routine cooperation of many people, it is often taken for granted by its bearer - though not, of course, by those who depend on the wise exercise of that power.

\section{Tightrope walking}

Let me start by reminding the reader of a famous sociological claim - that there is such a thing as the sick role, found in most societies. Like any role, the sick role involves obligations for both the person who occupies it and for those around her. The ill person is released from some social duties while others are obliged to offer support and assistance. This will not be held against the ill person providing she upholds her part of the bargain: she should not be to blame for her illness, and she should do her best to get better. ${ }^{8}$

This role works quite well where illness is temporary - either the person recovers after suitable time and rest, or medical interventions prove curative. Unfortunately, this is often not the case. Many people experience chronic illness, often several chronic illnesses. ${ }^{9}$ In

here in order to recognise this hierarchy. This is not to deny that nurses (for example) may be implicated in epistemic injustice, but only to suggest that the injustice tends to be more serious and intractable when professionals occupy positions of greater authority.

8 I loosely adapt Talcott Parsons' definition ( (33): 294). The sick role and its double binds are also well-discussed by Linda Alexander (34).

9 Chronic illness is little discussed in bioethics; the best article I know remains (35). Sociologists have done much better: I have learned especially from Anselm Strauss (36), (37)) and Sally Thorne and 
a revealing use of language, they 'fail to get better. ${ }^{10}$ However unfairly, the suspicion may arise that they are not doing their best to recover or that they are to blame for continued illness or even that their illness is put on. Such suspicions may arise where someone's suffering is blamed on 'lifestyle choices' (thus popular notions about obesity) or psychological problems. They are also likely to arise where no clear diagnosis or explanation can be found for the symptoms - either because medical science does not yet know, or because it is a rare condition. It is perhaps worth recalling that rare conditions, while rare by definition, are in another sense quite common. Shakespeare referred to the 'thousand natural shocks / That flesh is heir to' (Hamlet, Act 3, Scene 1). That might be a fair estimate of the common injuries and diseases, but if we add the rarer disorders, there would be far more. ${ }^{11}$ In such cases, professionals obviously face greater difficulties in helping, and the patient may be exposed to doubt - for instance, of malingering or hypochondria or exaggeration.

Especially where illness is chronic, and even more so where it is not (yet) clearly diagnosed or understood, occupying the sick role is like walking a tightrope. I offer the following, far-from-exhaustive list in order to indicate how demanding is the balancing act that the ill person must perform.

colleagues (e.g. (38), (39)). Arthur Kleinman's words remain sadly apt: ‘with such a ubiquitous problem, one can only marvel at the societal devices of denial that keep this normative aspect of life so well hidden' ( (40): 47).

10 Related failings of language are common. It is sometimes said that a patient 'fails' a therapy. Don Dizon recalls a wise colleague's rebuke: 'people do not fail chemotherapy. The chemotherapy didn't work, but no one failed.' (41); see also (42). Impairment of heart function are still referred to by the blanket term, 'heart failure.' John Launer (78) quotes Kasper and Knudson: 'Heart failure? No. Language failure, that's all.' Clinicians use the phrase 'failure to progress' to describe a labour that is advancing (too) slowly. Informing a mother-to-be that she is failing to progress is, as Myfanwy Williams has commented to me, pretty much the least helpful thing one may say to her. Varied as these examples are, they are united by their obliviousness to the patient's perspective.

11 The hindrances to diagnosis created by medics' disbelief and failure to listen to their patients, as well as over-reliance on standard categories and tests, are documented in (43). 


\begin{tabular}{|c|c|c|}
\hline \multirow[t]{2}{*}{ Language } & Patient & Active, responsible agent \\
\hline & Medical complaint & Don't complain \\
\hline \multirow[t]{2}{*}{ Appearance } & Look ill & Don't 'act ill' \\
\hline & Show seriousness of condition & Don't fixate on your illness \\
\hline \multirow{9}{*}{$\begin{array}{l}\text { Action and } \\
\text { feeling }\end{array}$} & Seek and ask for help & Cope, be dignified, put on brave face \\
\hline & Comply, adhere, behave, trust & Be self-reliant, take initiative ${ }^{12}$ \\
\hline & Accept help & Don't take advantage \\
\hline & Be grateful & Don't be pathetic \\
\hline & Reciprocate & Acknowledge your limitations \\
\hline & $\begin{array}{l}\text { Make others comfortable; don't } \\
\text { be difficult, demanding }\end{array}$ & $\begin{array}{l}\text { Enable them to understand your } \\
\text { situation, be your own advocate }\end{array}$ \\
\hline & Be positive & $\begin{array}{l}\text { Be realistic, don't engage in 'denial,' } \\
\text { acknowledge limits of medicine }\end{array}$ \\
\hline & $\begin{array}{l}\text { Make allowances, don’t expect } \\
\text { perfection }\end{array}$ & $\begin{array}{l}\text { Stand up for yourself, don't be a } \\
\text { doormat }\end{array}$ \\
\hline & $\begin{array}{l}\text { 'Life isn't fair' (so don't make a } \\
\text { beef about it) }\end{array}$ & $\begin{array}{l}\text { It is unfair that you're ill (you've } \\
\text { every right to feel the unfairness) }\end{array}$ \\
\hline
\end{tabular}

I will not comment on every item in this list, since it should take only a moment's reflection to appreciate the competing ideas and norms. (I will return to the question of who, in the thick of everyday life, is likely to give that moment.) But allow me to expand on just a few items.

In terms of the language used, consider the very word 'patient' - etymologically, one who undergoes and suffers - when patients are expected to be active in all sorts of ways, not least by taking a measure of responsibility to overcome or manage their illness. Or think of the problems bound up with how the sick person appears. She needs to show others that her condition is serious and that she merits special consideration (the sick role). ${ }^{13}$ But we generally demand that people cope, keep up appearances, do not 'act ill' or 'fixate' on

12 Sally Thorne and colleagues suggest that the ideal patient is 'both compliant and self-reliant' ((38): 303), but that these become 'mutually exclusive' in chronic illness.

13 On the special problems facing those with invisible conditions, see (79). 
their illness. How is the sick person to act? She should ask for and accept help; but woe betide her if she is suspected of taking advantage ${ }^{14}$ or being undignified. And then all sorts of dilemmas at the level of feeling: Grateful for the assistance provided, positive about her prospects, not wanting to impose an emotional burden on others. ${ }^{15}$ But what about her entitlement to help and fellow-feeling, or entirely natural emotions such as fear, anger, jealousy and bitterness?

There are several diagnoses one might offer for why this balancing act is both so necessary and so perilous. It might be that changing cultural norms are at work. It is often held that older ideas of the patient role involved deference to medical professionals. Attitudes of unquestioning trust are dying, and - so it is said - the idea of patient 'autonomy' is gradually coming closer to reality. ${ }^{16}$ One might look at the matter more moralistically. Perhaps ill people sometimes take on too much - imposing moral demands on themselves when the world is fully ready to make allowances for the difficult situation they are in. (I use the term 'make allowances' advisedly. It is, of course, another sort of balancing act to show consideration without condescension. ${ }^{17}$ )

Both of these explanations may have some truth, but they are contingent ones. The first explanation reflects a particular cultural constellation and only answers to some of the contraries on my list. The second relates to specific personal qualities that generate some of these contraries on a case-by-case basis. The structure of the 'sick role' provides a more universal explanation, less comfortable to contemplate. Ill people are exposed to judgment, and they are less able to offer their own judgments in return. In other words,

14 Compare the psychological jargon of 'secondary gain,' which convicts a patient of taking advantage and, quite possibly, of deceiving herself that she is doing so.

15 To expand slightly: The ill person is asked to appreciate that she carries a burden, not just for herself, but for everyone of good will (and who does not want to think of himself as bearing good will?), as well as for everyone who is afraid of illness, pain, disability and death (and who is not so afraid?).

16 Thus one might hope that some difficulties of medical communication have passed, such as those thematised in the important studies by Katz (44) and Kleinman (40). On the evidence of the papers cited here, fundamental problems in creating shared knowledge remain.

17 I thank Myfanwy Williams for reminding me of the broader point, familiar to all readers of Aristotle, that acting virtuously requires one to attain a 'mean' between two vices. This ancient insight accords with my overall argument. The demands of morality may become more stringent, to the point of incompatibilities that prevent a virtuous mean, the more difficult one's situation and the weaker one's power position. 
mutuality has faltered. As a result, dynamics of accountability falter too: they start to reinforce power differentials, rather than to criticise and redress misuses of power.

If we take a stance of specific good will toward another person, there is always a question as to how far our good will is merited. This means that the ill person is subject to a special sort of judgment - that she does indeed fulfil the requirements of the sick role: in fact ill, not in fact to blame, actually trying her best to get better or at least to manage. One may doubt the humanity of demanding that an ill person not be culpable for her illness, ${ }^{18}$ but the broader demand for evidence is surely reasonable. In any event, either demand can feed into a preparedness to scrutinise someone's condition and character - an attitude that would normally be criticised as intrusive. The situation of the ill person is such that these enquiries are harder to repel, since she is - implicitly or explicitly - asking that others show her special consideration, and so should demonstrate appropriate grounds for this.

This implies, in turn, that the judgments that motivate or issue from these enquiries have a special bite over and above our everyday judgments of one another. The situation is no longer one of full reciprocity. In one way or another, the ill person is burdened, lessened in her abilities to negotiate the world - whether fatigued or disabled or hurting or simply preoccupied with fear or worry. She must, therefore, lay herself open to others to elicit their help; by the same token, she is especially vulnerable to the withdrawal of whatever assistance is offered. The upshot is an unfortunate combination of obligations. She must demonstrate need without being 'needy.' She must reciprocate, not necessarily materially, but symbolically - that is, by showing gratitude. This puts the ill person in a weak position to stand up for herself. As we all know, it is already a tricky matter to hold others responsible while maintaining good relations with them. But the ill person is really on the back foot - since she is not meant to be 'demanding,' because she already bears special obligations of tactful demonstration and dignified gratitude. ${ }^{19}$

18 Or to put the point less moralistically: questions of responsibility and desert are notoriously tricky, and many accounts can be given of how culpability should be judged and what practical consequences it should carry. Hence the practical implications of this principle will be highly disputable. They will, moreover, vary considerably depending on what relationship one stands in to the ill person. For instance, official teaching is that healthcare professionals should not make or act on judgments of their patients' culpability; but norms governing friends' or colleagues' responses permit some space for such judgment. 
None of this is to impugn the moral character of those around the ill person, of those who do or might help. Perhaps these persons would welcome her requests, be glad of her challenges to complacency or insensitivity, respond constructively to signs that she is struggling to cope, and so on. Perhaps they would not indulge the dubious suspicion that the ill person bears some culpability for her illness and does not count among the 'deserving poor.' But the actuality of these 'perhaps'-s will rarely be clear to the ill person herself. Offers of help are not always heartfelt, and the heart is a double creature anyhow. People's willingness to accept criticism is fragile at the best of times, their ability to learn from it likewise. Not least, given our societies' wholesale manufacture of cod-psychology and its free retailing at every corner, frank admissions of distress always risk being read as signs of mental instability or psychosomatic causation.

In other words, the tight-rope can easily turn into a double bind. And the ill person has every reason to be alive to this risk, to fear or feel the rope tightening, even when those around her do not intend this.

\section{Double binds and paths of least resistance}

The idea that people in weaker power positions often face double binds is an old one. This is how Marilyn Frye put the point:

One of the most characteristic and ubiquitous features of the world as experienced by oppressed people is the double bind - situations in which options are reduced to a very few and all of them expose one to penalty, censure or deprivation. For example, it is often a requirement upon oppressed people that we smile and be cheerful. If we comply, we signal our docility and our acquiescence in our situation... We participate in our own erasure. On the other hand, anything but the sunniest countenance exposes us to being perceived as mean, bitter, angry or dangerous. This means, at the least, that we may be found 'difficult' or unpleasant to work with... One can only choose to risk one's preferred form and rate of annihilation. $^{20}$

ill person. As observed earlier, this is not to deny that ill people may sometimes wield morality against themselves - indeed, to some extent this is just what we expect every responsible person to do.

20 (45): $2 \mathrm{f}$. Frye then gives the example of the identities attached to women in terms of their sexual activity - 'frigid,' 'lesbian' or 'whore': 'Both heterosexual activity and heterosexual nonactivity are likely to be taken as proof that you wanted to be raped, and hence, of course, weren't really raped at all. You can't win. You are caught in a bind, caught between systematically related pressures.' 
In her book, Illness, Havi Carel highlights the same issue in terms of social expectations upon the ill person. She titles one section, flatly, 'Learning to be rude' ( (5): 45). People look for evidence of illness, which can already amount to an intrusion. At the same time, they dislike being confronted with the uncomfortable and frightening physical realities. So the ill person must be on her guard, pre-empting misunderstanding and fending off affronts: 'the need to be on your toes, to be ready for an attack - deliberately ruthless or naively insensitive - ... on you as an individual whose life trajectory is different; as someone who looks different; as a stigmatized individual whose condition is feared and denied by those surrounding you' ( (5): 48). Either the sick person makes continual allowances for fear and incomprehension - adding the acceptance of insult to the injury of illness. Or she takes a defensive and combative stance - and risks being thought of as paranoid or hostile. In other words, she learns to be rude. The situation is a classic double bind - open to blame or disadvantage either way, 'damned if you do, damned if you don't.'

More than the social pressures, however, I want to emphasise how analogous problems can arise in the medical context. One might hope they would not. These are the helping professions, entirely familiar with need and bodily frailty, official authorities on what it is to be sick. But they are also, for these reasons, the places where obligations of demonstration and gratitude bite especially hard, alongside the realities of dependence and expertise. Morally speaking, the ill person is obliged to lay herself open, to acknowledge professionals' insight and judgment and good will. Institutionally, she is obliged to accept their authority, inasmuch as she depends on professionals for whatever services, investigations and treatments may be helpful to her, and insofar as she finds herself on unfamiliar ground, ${ }^{21}$ with strictly limited access to those who might listen and assist. All these factors leave the ill person especially ill-placed to protest unreasonable treatment.

Sometimes the double binds are straightforwardly practical, especially if a patient feels critical about the organisation or delivery of medical services. For example, a person who depends on nursing care may well find some of her bodily needs ignored, or suffer thoughtless or degrading treatment. Most patients know better than to complain about this: ward staff have many ways of making their displeasure known to a complaining patient, and there may still be much to be grateful for. Bodily dependence, moral obligation, institutional powerlessness - these act together to stitch the patient up in a

21 On the latter point, as a general problem for clients of complex bureaucracies, see (46). 
double bind. The patient who suffers organisational carelessness is precisely the one who dare not speak. If she does speak, the knot is likely to tighten further. Either way, others' perspectives win out over hers.

Or consider the double binds that arise when the patient's other specialist area of knowledge is disallowed - by which I mean: not just about how others treat her, but about her own body. Here, the patient's own account of her suffering - such as her symptoms and their history, or the side-effects of a drug or treatment - is either ignored or rationalised away.

Ignored: the patient's account of the symptoms or problems that she is experiencing is not properly elicited or not fully heeded. It is always possible that health professionals will interrupt or rush or misinterpret a patient's speech. In many situations, there are special temptations not to acknowledge or credit her. ${ }^{22}$ If symptoms do not correspond to common or recognised disease processes, if a person suffers several different illnesses that interact in unusual or unexpected ways, if test results do not provide objective verification, if symptoms (as in the case of pain) simply do not permit such verification, ${ }^{23}$ if side-effects are not already recognised - in each case, there is a standing pressure to discount what the patient says. ${ }^{24}$ Of course, professional responsibility militates against this. After all, medical expertise only counts when applied to the patient's actual symptoms and suffering. Nonetheless, time pressures, various implicit biases that disadvantage the ill person, ${ }^{25}$ the relatively weak position occupied by the patient herself,

22 That is, beyond the simple fact that patients are fallible human beings, who sometimes lie, confabulate, exaggerate or misinterpret their symptoms, or have unreasonable expectations of medicine or medical institutions. These possibilities may provide reasons to discount a patient's views - or merely convenient rationalisations.

23 The literature exploring the problems faced by patients with chronic pain is vast and distressing. I note only one article by the philosopher Laura Ekstrom (80). She observes some of the notorious double binds faced by these patients (for examples: be stoical, and be told that your pain cannot be serious / show distress, and be judged as deranged; ask for more pain relief, and be judged as an addict / do not ask, and suffer further). She argues for the importance of physicians' compassion; I am pointing to the need for wisdom, accountability and institutional learning, too.

24 Hence patients' oft-reported feelings of being 'on trial' in the clinical encounter (23); hence patients' attempts to provide evidence of their credibility and good character, no doubt sometimes counterproductive (47).

25 'Implicit bias' denotes prejudice that someone is unaware of holding - for example, the person who consciously believes that men and women are equally competent, but whose actions reveal greater credence in a man's statements and suggestions. Ian Kidd (48) discusses this problem and its contribution to epistemic injustice in healthcare. 
reliance on standard tests or evidence-based guidelines (6) (7), the wish to offer an established diagnosis and recognised treatments - all push matters in the other direction. In other words, the path of least resistance is often to ignore or disbelieve some of what the patient might say or has said. This naturally presents the patient with a double bind. She can submit to measures that are unlikely to address her actual problems, whether these be a particular diagnosis and accompanying prescriptions, or standard but misdirected tests, or bland reassurances that bypass her actual complaint ('nothing to worry about,' 'within the range of normal variation,' 'we find these things usually go away by themselves'). ${ }^{26}$ Alternatively, the patient can marshal whatever resistance is within her power, insisting on her symptoms and suffering as she experiences them. But every patient knows how risky this is. To assert her own expertise looks like a challenge to the medical expert whose help she seeks (8); she may find herself labelled difficult, controlling, non-compliant ${ }^{27}$ - or worse, as subject to some sort of mental pathology or failing.

In this last case, symptoms and side-effects are not so much ignored as rationalised away. They are downplayed in terms of the suffering they involve and the diagnostic significance they have, not to mention the worry they naturally elicit. Professionals might accept that there are bodily effects - thus the 'somatic' in 'psychosomatic, ${ }^{, 2}$ the (dys)'function' in 'functional,' the symptoms that remain 'medically unexplained. ${ }^{29}$ But their

26 Not to mention reassurances that are meaningful ('the test results are all normal,' for example) but provide little reassurance since they shed no light on the source of symptoms and suffering.

27 As Søren Holm argues (81), this is another revealing and damaging use of language. If one is dealing with a competent, autonomous adult who enjoys a fundamental right to self-determination, then the idea of 'compliance' is simply out of order. See also (35): 11f. Whether the term 'adherence' is any better could be debated - cf (49). As I suggest throughout this chapter, language may reveal uncomfortable realities; but linguistic reforms cannot alter underlying power relations.

28 As Norma Ware observes, 'Despite the fact that psychosomatic medicine was originally conceivable as an antidote to biological reductionism, an attempt to bring mind and body together in biomedicine in more or less equal union, in reality psychosomatic diagnoses have come to be classed with psychiatric disorders, reproducing dualistic thinking and sharing the stigmatized status of mental illness as a disability we "bring on ourselves"" ( (82): 356).

29 The latter term covers a range of conditions such as chronic fatigue syndrome, irritable bowel disease, and fibromyalgia. Many further terms make explicit psychological attributions: 'psychogenic pain,' 'secondary gain,' 'disease conviction,' 'symptom vigilance,' 'health anxiety,' 'catastrophising,' and more. Clearly much might be said about these categories (e.g. (50), (51), (83), (47), (52), (84)). I note just two points that bear on my central theme. 
specific nature loses importance, since they are now seen as a product of the patient's own activity - perhaps a lack of 'compliance,' or else as manifestations of anxiety, exaggeration, depression, fixation, 'somatisation' and so on. Now, invoking some of these categories could represent a starting point for serious psychological help. Depending on one's optimism about the diagnostic capacities of the psychiatric professions, ${ }^{30}$ perhaps this would discover whether psychological help is in fact needed - or, alternatively, and as common sense and common humanity suggest is rather likely, if a patient's distress is the result of experiencing unpleasant and worrying bodily symptoms, and finding medical authorities less heedful than they ought to be and less helpful than one might hope.

First, one might frame the issues here in terms of Fricker's 'hermeneutical injustice,' as Blease et al (85) note in the case of chronic fatigue. Both patients and professionals are left struggling with categories that are inadequate and stigmatising. Of course, 'injustice' does not arise simply because medical understanding is inadequate - that may be nobody's fault, since so many medical problems elude our best efforts to understand them. But we may speak of injustice where a condition is regarded with less seriousness than it deserves or suffers a culpable lack of research, or where stigmatising hypotheses such as 'psychogenesis' are given undue weight in shaping categories, applying labels, and handling patients.

A second point is that many of these terms involve linguistic violence that puts the patient in a prejudicial position. Two examples. 1. Taken literally, the term 'medically unexplained symptoms' means symptoms which medics do not (yet) know how to explain. Sometimes these are quite awful, and surely more worrying for the patient given lack of explanation, not to mention adequate treatment. However, standard use of the term implies that symptoms should be 'explained' in psychosomatic (or slightly more generously, psychosocial) terms. Since the channels by which psychological difficulties give rise to physical symptoms remain speculative, this is an unsubstantiated allegation rather than a meaningful etiology. Reasonable words are abused to connote the unreason of a particular class of patients who are, one might otherwise conclude, let down by the current state of medical knowledge. 2. 'Health anxiety' involves an even more flagrant abuse. If one's health is failing in some way, anxiety is the normal human reaction. Yet health professionals now use the term to connote a close cousin of hypochondria, involving unreasonable anxiety about a problem that is less real than the patient takes it to be. Words that we would normally use to describe a normal response are annexed to denote psychopathology, thus erasing the normal response itself - one that ought to be all the more understandable, the more a condition remains undiagnosed, unexplained, inadequately treated, uncured and quite possibly incurable.

30 In line with many critiques of the psychiatric professions (e.g. (53)), I doubt there is much room for optimism here. Since the definition and judgment of rationality is so contestable, since failings of rationality are ubiquitous, and since the relation between our partly rational minds and partly recalcitrant bodies is so intricate, professionals tasked to locate mental failings are unlikely to fail in their task. This is especially likely if other medical professionals have already suggested that a patient's own account of her symptoms is not credible or her illness is 'unexplained' - that is (following the linguistic violence noted in n.29), 'explicable only on a psychogenic basis.' 
Rather more often, however, these imputations rationalise attributions of responsibility to the patient, or withholding endorsement of the seriousness of her condition and reality of her suffering, or explaining away any perceived disparity in perspective between clinician and patient. Again, these categories supply a path of least resistance. This is not to deny that they may be used with honourable intent and sometimes point to real phenomena. My point is that they create a peculiarly stringent double bind for the patient. They discredit the patient's voice, belittling her as a person who is - however unwittingly, however unwillingly - no longer sovereign in the fragile castle of her skin. ${ }^{31}$ Equally, they cast the patient into a passive role, with everything that promises in terms of inadequate care and on-going illness. ${ }^{32}$ If she attempts to take responsibility, to venture a different opinion, to pursue further treatments or investigations, to assert her standing as a capable judge of her own symptoms and needs, to insist that any anxiety or preoccupation she feels is the natural emotional counterpart of legitimate self-concern and self-responsibility, let alone to point out that such feelings are only exacerbated if health professionals prefer to emphasise her mental state ${ }^{33}$ rather than the symptoms she complains of... - in general, if she tries to speak or act on her own account, this can be discounted as further evidence of lack of insight or rationality, of resistance or fixation or obsessiveness or denial or some other derangement.

To underline the ways in which patients may be trapped is not to deny that those who care for ill people may walk tightropes or be caught in double binds of their own. It may be hard for loved ones to show concern for the situation of an ill person, without prying or insensitive reminders. One is meant to help but not to make the ill person feel helpless ( (5): 57). Having emphasised how disabling the categories of the 'medically unexplained' are for patients, it also bears saying how they create binds for practitioners. Their murkiness always threatens to override individual practitioners' own good intentions and

31 Freud famously claimed that the 'ego is not master in its own house' ( (86): 143). Whatever one thinks of this teaching, he was wise enough to recognise that it applies to doctor and patient alike.

32 As Malterud \& Taksdal put it, 'When the patient's credibility is questioned... the focus of objectification is already in the process of shifting from complaint to patient' ( (47): 33): the difficult illness transmutes into a difficult patient.

33 The overuse and misuse of 'depression' might also be mentioned here. While depression is surely one of the most solid categories in the psychological lexicon, the frequency with which it is invoked to help explain symptoms or their severity is itself depressing. As should be obvious, most of the emotions and responses that come under the head of depression also represent entirely natural responses to the reality of long-term illness. 
attempts to convey regard for the patient ${ }^{34}$ - especially when psychoactive medications such as anti-depressants form the main therapeutic option. Not least, what about the situation of professionals who lack time and other resources to provide proper care? There may not be time to listen and draw out a patient's account; giving optimal treatment may prove impossible. Hence to treat some patients properly is to neglect others or risk burn-out. Just as important, doctors who care about their patients are bound to find chronic illness frustrating, just as they will find it hard to bear the suffering that patients experience and, sometimes, their inability to alleviate it. ${ }^{35}$ If honourable concern creates a heavy emotional burden, then dishonourable distancing tactics - failures to listen and believe, victim-blaming and the rest - may provide a path of lesser resistance, provided they are not acknowledged as such. ${ }^{36}$

34 For example: 'I'm not saying it's [all] in your head,' 'there are many things we still don't how to explain,' 'lots of patients with long-term illness benefit from psychological support.' From the patient's perspective such disavowals are more likely to add confusion than to remove the basic insult - projecting medicine's lack of understanding onto the patient, by implicitly accusing her of a lack of self-understanding. (Or indeed explicitly, as in attempts at 'reattribution': see the useful discussion (54).)

35 This is well expressed by (55). In old-fashioned terms, medical professionals are asked to bear witness to much that is most fearful in human life. It is not mysterious that this call to witness has been partly lost from sight, given the enormous successes of modern medicine in treating many ailments, as well as doctors' and patients' all-too-understandable orientation toward cure and alleviation. The underlying difficulty is twofold: recalcitrant and rare conditions can only be addressed by paying proper attention to their manifestations (that is, by bearing witness); sometimes all that medicine can do, short of abandoning a patient to her fate alone, is to bear witness. (On threats of abandonment, see also (56).)

36 On distancing tactics, see (57) (58). Let me also note two further binds. There may be difficulties in combining professional responsibility with patient self-management, insofar as patients are liable to make mistakes - or at least, more likely to make some mistakes, just as, on my argument, they are less likely to make others. See: (34); (59); (60); (61). Another problem is noted by (3): 532: clinicians risk giving patients too much as well as too little credibility. In cases of factitious illness - that is, frankly invented or self-inflicted symptoms - every plausible course of action is attended by risks and even penalties. Savino \& Fordtran's well-judged discussion ( (62)) includes the cautionary tale of a man's prolonged and agonizing death by necrosis of his small intestine. The following was written in his case notes three days before he died: 'the pain syndrome seems psychogenic in origin (not a depressive equivalent) and secondary to his dependent narcissistic personality structure' (quoted 206). Cod-psychology can kill as cruelly as any disease. 
Organisations and professions are power structures, and double binds can arise at every level. But the weaker one's power position, the more often double binds will arise and the harder they will be to protest. As a rule, it is patients who have the least power.

\section{The invisibility of power positions to those who occupy them}

Let me turn now to the last item in my title. I can illustrate it with the example of my own institutional role. As a university lecturer, I do not feel especially powerful. Although I value many of my responsibilities, there is no doubt that I must act within many constraints and requirements. Matters look very different to my students: my words carry a certain authority, which exceeds theirs; I have the power to determine what they should learn and to award them grades; my judgments of them may operate in ways that are not conducive to their interests. ${ }^{37}$ My students are unlikely to forget this power, but I do not need to think about it. Nothing forces me to dwell on the factors that enable me to do my job: the institutional support and professional recognition that give me authority; the routine familiarity with organisation and colleagues and procedures; my students' trust and even deference; the relations of dependence in which they stand to me. Like most professionals, I gained this authority slowly: to reach my position involved effort, struggle and set-backs. ${ }^{38}$ And my normal focus remains on obstacles to my work ${ }^{39}$ or ambitions I have yet to attain. We always chafe against constraints. But abilities and enablements, like the sheer, silent functioning of a healthy body (9), are matters we may take for granted. Not so, for someone who relies on our power to act, and who must suffer if we do not exercise it to her benefit. ${ }^{40}$

37 Perhaps this is not so, but the fear is not unreasonable, since the institutional set-up is less familiar to them $-\mathrm{cf}(46)$.

38 So it is not unknown, for example, to encounter a senior colleague who still behaves as if he were more junior: overly solicitous of the great and the good; careless of the harm his words and deeds might do to those less senior - what care, after all, need one exercise if one is relatively powerless?

39 For example, the ways in which rules or procedures hinder my work. Of course this may represent a merely subjective judgment, perhaps only a hairsbreadth from 'obstruct my immediate preferences.'

40 It is also worth noting the problems of projection that can arise. Professionals sometimes project power onto patients, by labelling them as 'controlling' or some such. Similarly, professionals may take the fact that a patient can (sometimes, with sufficient determination) cause them real trouble as sign that the patient has power. But the fact that patients may go down various organisational or 
I take it the same thing applies to health professionals, even to those in positions with the greatest power, prestige and remuneration. Setbacks are common: grant applications rejected, promotions denied, the various slights that we are all liable to receive or at least to perceive. For all the frustrations they sometimes cause, organisations function moreor-less invisibly, because they are comprised of other people's initiatives and cooperation. A consultant, for example, can rely on pharmacists to dispense (but only on his say-so), on investigations taking place (but only as he directs), on appointments systems to function and patients to wait their turn. The list could go on.

Another way of putting this is that we have every reason to pay attention to the opinions of those who have the power to frustrate our aims and ambitions, and few reasons to notice the factors that enable us to act on an everyday basis. Like my students, patients usually lack the power to frustrate a professional's actions. Hence their opinions and voices are weak reeds. Patients may have some choice about whether to 'comply' with prescriptions. But they have no choice but to comply with key institutional rules - for example, the occasional opening of whatever gates may permit them access to professional attention and services. ${ }^{41}$ No doubt, this must be so. My point is only that individual practitioners need not pay any special regard to the resulting power structure. ${ }^{42}$ Each professional is responsible for implementing few of its components; only rarely does it obstruct his efforts and initiatives; the organisation's daily reality as taken-for-granted for him as it is strange and fraught to his patients. ${ }^{43}$

In terms of my theme, epistemic justice, medical professionals' most weighty and decisive power is the power to diagnose (10); other health professionals join in this power insofar as they help assess symptoms and the character and credibility of a patient. This power is not just epistemic, however, but also practical: it represents the key to investigations, treatments, alleviations and much more. To an individual professional,

legal warpaths is hardly a sign of their power, and much more a token of how a sense of humiliation and impotence can create lasting anger. A determined complainant may extract monetary compensation or even legal vindication, and cause much institutional gnashing of teeth along the way. It is much rarer for her to get the only things that can give meaning to her suffering and mistreatment: honest acknowledgement and organisational learning.

41 For one pointed description of these dynamics, see (63).

42 Parallel points apply to the organisation itself: it requires determined effort for an organisation to appreciate the actual experience of patients who must navigate its offices, wards and corridors.

43 Of course it may: for instance, when a doctor struggles to obtain a referral or an investigation; or more generally, when professionals battle with limited resources. But even in such cases, there is less at stake for professionals than patients: it is patients' health and wellbeing that are on the line. 
however, it is unlikely to be experienced in these terms. More likely, it will seem like a responsibility, often a weighty one. Sometimes it may be accompanied by uncertainty and anxiety - especially likely where medical power in its most indisputable sense of the power to cure has proved wanting. But the fact remains: Professional power to diagnose is the socially and institutionally accorded authority to define the nature and reality of another person's illness. Another medic may later offer a different diagnosis, of course, or register surprise that particular possibilities have not been considered. But only rarely will this involve frank criticism of earlier professional judgments.

Dorothy Rowe once made the stunning claim: 'In the final analysis, power is the right to have your definition of reality prevail over all other people's definition of reality' ( (11): 16).$^{44}$ I suspect most health professionals would boggle at this dictum and any purported relevance to their practice. Certainly, the claim does not do justice to the immense relief patients can experience when professionals make sense of symptoms and suffering, creating knowledge where there was confusion and worry. ${ }^{45}$ This power to make sense of intimate but opaque realities matters enormously, even where it does not lead to tangible remedy or cure. Nonetheless, there is a dark side to this power, and I think Rowe's words will strike a chord with many patients. It is an experience that medical professionals need not consider: the patient's feeling, not just that she is doubted or discredited by those who are responsible for diagnosing and defining her condition, not just that so many medics show a granite incuriosity as to what ails her, but also that she finds herself disempowered, humiliated and isolated. ${ }^{46}$ Where others dismiss or disparage the reality that someone deals with - in the case of chronic illness, a reality that a person must deal with day after day after day, in the most intimate and inescapable and undeniable way (12) - that person is robbed, not only of the possibility of illuminating diagnosis or helpful treatment, not only of authoritative advocacy as she navigates the labyrinth of referrals and investigations, but also of the most basic consolations of respect and mutual understanding. The person's definition of reality cannot prevail: it is professionals who define her condition. In the limit, the pronouncement of 'medically unexplained symptoms' functions, not as an imperative demanding further investigation, not as a condemnation of medical failure, but as a label denoting a basket case for whom nothing

44 I thank Nancy Blake for bringing this quote to my attention.

45 My thanks to Myfanwy Williams for this point.

46 Many socio-medical studies have explored this theme, following Aaron Lazare's seminal article (64). See e.g. (65), (66), (67). 
can be done because everything already has been done, a hopeless case which no medical professional need invest more effort in, a patient whose complaints no one must heed.

In situations where there is no uncontestable, objective evidence of illness, or where the patient remains without access to investigations that would yield such evidence, or where the nature of the illness eludes standard diagnoses, or where symptoms or side-effects somehow fail to conform to recognised processes - and these situations are more common than we like to think - the only thing that stands in the way of such abandonment is the patient's own voice. But this is a voice that already lacks credibility, that has already been deemed non-authoritative. As a result, there is no reason to think that the patient's protests can offer effective resistance. The same is often true in situations where patients experience inadequate care or unwarranted institutional demands. Most often, there is only the patient's voice, or perhaps that of loved ones or a patient advocate, to testify to this. So again the double binds: Whether to speak up or not, neither seems likely to help. Perhaps even worse: without medical institutions, the patient is on her own, ${ }^{47}$ in the face of medical doubt and dismissal, she is equally isolated. These double binds arise, not from ill will, but from structures of knowledge and power that create paths of least resistance for professionals and place patients in a weak position to resist: expected to acknowledge both the expertise of medical professionals and the limited powers of modern medicine; expected to be grateful for the help they receive but unable to set the terms on which that help is defined and provided; not always able to demonstrate their suffering or symptoms; ill-placed to refute insinuations against their insight or honesty or integrity or rationality or even sanity.

\section{Conclusion}

All professions and organisations face difficulties in living up to their official responsibilities; customers, members, or clients face corresponding difficulties in holding them to account. As the first line of institutional defence, there is always some version of the 'few bad apples' theory, while wider criticisms can be discounted as implausible allegations of 'many bad apples.' We all know that a few bad apples are inevitable; insiders know that they are 'good chaps' and have every right to dismiss allegations of many bad apples. Thinking in terms of bad apples, we never get to the heart of the matter:

47 Of course, there is an alternative, of sorts: alternative medicine. That patients are willing to invest in this is often taken as a sign of their irrationality. This view is certainly more comfortable for the medical profession than reading it as an indictment of the care that these patients have thus far experienced. 
how organisations and roles work together to create power positions, biases, and blindspots. As a result, organisations and professionals often lack self-knowledge, a basic condition of practical wisdom. They may still use their power to do much good service. But they will also act against the interests of some they are meant to serve.

This chapter has focussed on the medical case, and the specific dynamics that infect it. Perhaps more than any other institution, medicine depends on the knowledge of those it is meant to serve. The sick person is the privileged observer of her body; she alone knows the day-in-day-out dynamics of her illness, the day-in-day-out effects of treatments, which medical expertise must accommodate on pain of betraying itself and the person it would help. Unless she is wholly incapacitated, it is the patient who moves between various offices and specialists and organisational niches; amid the inevitable fragmentation of modern medical systems, she alone witnesses each aspect of her treatment. She knows how the system works for her, the demands that it imposes on her, and how it fails her. She knows this in a way that no medical professional does.

I will not belabour any further the power dynamics that make these epistemic privileges more dubious than they are by their very nature - less helpful than they should be in deepening medical understanding of the infinity of shocks that flesh is heir to, less useful than they should be in teaching professionals and organisations how to care for patients. But I do want to point out one more feature of double binds that disempowers patients as well as those tasked to help them. Many decades ago Gregory Bateson and colleagues suggested that schizophrenia might be caused by systematically exposing a child to double binds. They pictured these binds as having the following structure:

1. A primary injunction that says that, if the person acts in a certain way, she will face negative consequences: e.g. 'Do not do so and so, or I will punish you.'

2. A conflicting injunction that is more abstract than the first, and is communicated non-verbally, but which also carries the threat of negative consequences: e.g. 'Do not see me as the punishing agent,' or 'Do not notice the unfairness of my actions.' $(1)^{48}$

48 At 253f. This pictures both injunctions as issuing from same source. But they need not: one parent may undermine the other's injunctions; social or institutional norms may run counter to injunctions of a particular professional. Bateson also invoked a 'tertiary injunction,' prohibiting escape from the situation. I need hardly point out that there is no escape from illness, short of cure or suicide, and that to withdraw from medical institutions is to give up on hope of cure or alleviation. 
Explained in this way, the unfairness is clear. However, such situations are not explained and the injunctions only partly articulated. This obscurity breeds confusion. It makes it hard for the victim to understand and justify her sense of frustration, humiliation, isolation and the rest.

If the reader has heard some slight echo of Erving Goffman's work here - for example, his account of the 'betrayals' suffered by the incarcerated mental patient (13) - I will be very glad. I am suggesting that the ill person is oppressed, not just by illness but also by the moral demands of a considerate, right-thinking world, and by the rationalisations that draw a veil over its unreason. Amid competing pressures and imperatives, such as are bound to arise in complex organisations, professionals will tend to follow whatever paths of least resistance open up. These paths are paved with materials both solid and shoddy: good intentions; legitimate authority; hard-won expertise; professional distance; standard categories, tests and treatments; trust in evidence; mistrust of 'mere anecdote'49; recording and reporting systems oriented to professional and institutional imperatives rather than patients' experiences; limited time and scarce resources; unseen biases; lack of imagination; abuses of language; victim-blaming; emotional distancing tactics; fear of admitting failure - and more. Slipperiest of all are the psychogenic categories that undermine patients' already limited credibility: always on hand to absolve medicine when it fails to explain or help; always paid for by patients rather than professionals; rarely open to rebuttal by the patients they denigrate, and never without further risks to their standing.

Too often, then, patients find themselves in double binds. But those double binds are hard to see and hard to address. Because patients already face challenges in articulating their experiences and barriers to speaking out, challenging authority, or even holding professionals accountable, epistemic injustice is marked by a vicious circle. Attempts to overcome double binds - or simply to voice the justified and reasonable emotions of 'helplessness, fear, exasperation, and rage' ( (1): 261) to which they give rise - are obstructed by those same binds. Complainant, complainee, and the world at large - all may interpret such efforts as evidence of immorality (ingratitude, unreasonable expectations, weakness) or irrationality (denial, fixation, and the rest). Moreover, because power hides from its holders and none of this intended, the situation tends to be even more obscure from the other side. The binds emerge despite, not because of, the intentions of professionals and the institutions to which they belong.

49 Concerning how the last two points may operate against patients, see (68) (69) (6) (7). 
Where our normal ways of seeing obscure insights and experiences, then we suffer a particular sort of hermeneutical injustice. To articulate that injustice is already a small step in bringing justice to bear. Beyond this point, admittedly, this chapter has not sought solutions. Many possibilities are on the table. Carel \& Kidd (3) propose a toolkit to help articulate patient experiences and its use in clinician training; we may also think of efforts to involve patients in (re)designing services (14), mechanisms for patient advocacy and organisational learning (including improvements to complaint systems and measures to ensure patient safety), the recognition of expert patients, ways to incorporate patients' priorities in research (15), lessons from medics who have become patients (16), (17), the many roles that patient organisations can play, not to mention other strategies belonging to person-centred healthcare. Here my aim has been more limited - to help diagnose and explain one of modern medicine's chronic conditions: epistemic injustice, a barrier to medical insight and an obstacle to all attempts to focus medical care on the person who needs it. Because this injustice undercuts forms of accountability that would challenge it, I fear that complete cure may be beyond reach. Nonetheless, meaningful alleviations are surely possible - so long as we are sure that the complaint is real, the diagnosis valid, the symptoms neither inexplicable nor 'unexplained.'

\section{Bibliography}

1. Bateson G, Jackson DD, Haley J, Weakland J. Toward a theory of schizophrenia. Behavioral Science. 1956; 1(4): p. 251-264.

2. Fricker M. Epistemic Injustice: Power and the Ethics of Knowing Oxford: Oxford University Press; 2007.

3. Carel H, Kidd I. Epistemic injustice in healthcare: a philosophical analysis. Medicine, Health Care and Philosophy. 2014; 17(4): p. 529-540.

4. Kidd I, Carel H. Epistemic injustice and illness. Journal of Applied Philosophy. 2017; 34(2): p. 172-190.

5. Carel H. Illness: The Cry of the Flesh Stocksfield: Acumen; 2008. 
6. Greenhalgh T, Snow R, Ryan S, Rees S, Salisbury H. Six 'biases' against patients and carers in evidence-based medicine. BMC Medicine. 2015; 13: p. 200.

7. Miles A, Loughlin M. Models in the Balance: Evidence-Based Medicine Versus Evidence-Informed Individualized Care. Journal of Evaluation in Clinical Practice. 2011; 17(4): p. 531-536.

8. Frosch DL, May SG, Rendle KAS, Tietbohl C, Elwyn G. Authoritarian physicians and patients' fear of being labeled 'difficult' among key obstacles to shared decision making. Health Affairs. 2012; 31(5): p. 1030-1038.

9. Toombs SK. The metamorphosis: the nature of chronic illness and its challenge to medicine. Journal of Medical Humanities. 1993; 14(4): p. 223-230.

10 Jutel A. Putting a name to it: Diagnosis in contemporary society Baltimore: Johns . Hopkins University Press; 2011.

11 Rowe D. Foreword. In Masson J. Against Therapy. London: Fontana; 1990.

12 Toombs SK. Illness and the paradigm of lived body. Theoretical Medicine and . Bioethics. 1988; 9: p. 201-226.

13 Goffman E. Asylums: Essays on the Social Situation of Mental Patients and Other . Inmates: Pelican; 1968.

14 Ziebland S, Coulter A, Calabrese JD, Locock L. Understanding and using health . experiences: improving patient care Oxford: Oxford University Press; 2013.

15 Chalmers I, Atkinson P, Mark Fenton FM, Firkins L, Crowe S, Cowan K. Tackling .treatment uncertainties together: the evolution of the James Lind Initiative, 20032013. Journal of the Royal Society of Medicine. 2013; 106(12): p. 482-491.

16 Klitzman R. When Doctors Become Patients Oxford: Oxford University Press; 2008.

17 Tomlinson J. BMJ Careers. [Online].; 2014. Available from: . http://careers.bmj.com/careers/advice/view-article.html?id=20017843. 
18 Wylie A. Why standpoint matters. In Figueroa R, Harding S, editors. Science and . Other Cultures: Issues in Philosophies of Science and Technology. New York: Routledge; 2003. p. 26-48.

19 Rouse J. Power/knowledge. In Gutting G, editor. The Cambridge Companion to . Foucault (2nd edition). Cambridge: Cambridge University Press; 2005. p. 95-122.

20 Baehr J. Virtue epistemology. In B Dowden \& J Fieser (eds) Internet Encyclopaedia . of Philosophy. [Online].; 2004. Available from: http://www.iep.utm.edu/virtueep.

21 Haddock A, Millar A, Pritchard D, editors. Social Epistemology New York: Oxford . University Press; 2011.

22 Kidd IJ. Epistemic injustice and illness bibliography (updated 24/1/17).. [Online].; .2017. Available from: https://www.academia.edu/30136837/Epistemic_Injustice_and_Illness_Bibliograph y.

23 Werner A, Malterud K. It is hard work behaving as a credible patient: encounters . between women with chronic pain and their doctors. Social Science \& Medicine. 2003; 57(8): p. 1409-1419.

24 Malterud K, Candib L, Code L. Responsible and responsive knowing in medical . diagnosis: the medical gaze revisited. NORA - Nordic Journal of Feminist and Gender Research. 2004; 12: p. 8-19.

25 Håkanson C, Sahlberg-Blom E, Ternestedt BM. Being in the patient position. . Qualitative Health Research. 2010; 20(8): p. 1116-1127.

26 Lillrank A. Back pain and the resolution of diagnostic uncertainty in illness . narratives. Social Science \& Medicine. 2003; 57(6): p. 1045-1054.

27 Newton BJ, Southall JL, Raphael JH, Ashford RL, LeMarchand K. A narrative . review of the impact of disbelief in chronic pain. Pain Management Nursing. 2013; 14(3): p. 161-171.

28 Price E, Walker E. Diagnostic vertigo: the journey to diagnosis in systemic lupus . erythematosus. Health. 2014; 18(3): p. 223-239. 
29 Cassam Q. Diagnostic error, overconfidence and self-knowledge. Palgrave . Communications. 2017; 3: p. 17025.

30 Freeman L. Confronting diminished epistemic privilege and epistemic injustice in . pregnancy by challenging a 'panoptics of the womb'. Journal of Medicine and Philosophy. 2015; 40(1): p. 44-68.

31 Kurs R, Grinshpoon A. Vulnerability of individuals with mental disorders to . epistemic injustice in both clinical and social domains. Ethics \& Behavior. 2018; 28(4): p. 336-346.

32 Malterud K, Ulriksen K. Obesity, stigma, and responsibility in health care: a . synthesis of qualitative studies. International Journal of Qualitative Studies on Health and Well-Being. 2011; 6(4): p. 8404.

33 Parsons T. The Social System London: Routledge; 1991.

34 Alexander L. The double-bind between dialysis patients and their health . practitioners. In Eisenberg L, Kleinman A, editors. The Relevance of Social Science for Medicine.. Dordrecht: D Reidel; 1980. p. 307-329.

35 Jennings B, Callahan D, Caplan AL. Ethical challenges of chronic illness. Hastings . Center Report. 1988; 18(1): p. 1-16.

36 Strauss A. Chronic illness. Society. 1973; 10: p. 33-39.

37 Strauss A. Health policy and chronic illness. Society. 1987; 25: p. 33-39.

38 Thorne S, Ternulf Nyhlin K, Paterson BL. Attitudes toward patient expertise in . chronic illness. International Journal of Nursing Studies. 2000; 37(4): p. 303-311.

39 Thorne S, Harris SR, Mahoney K, Con A, McGuinness L. The context of health care . communication in chronic illness. Patient Education and Counseling. 2004; 54(3): p. 299-306. 
40 Kleinman A. The Illness Narratives New York: Basic Books; 1988.

41 Dizon D. ASCO Connection. [Online].; 2012. Available from: . https://connection.asco.org/blogs/power-words.

42 Gordon S. BMJ Blogs. [Online].; 2015. Available from: . http://blogs.bmj.com/bmj/2015/12/07/suzanne-gordon-medicines-f-word-fail/.

43 EURORDIS. EURODIS (Rare Diseases Europe). [Online].; 2009.

44 Katz J. The Silent World of Doctor and Patient New York: Free Press; 1984.

45 Frye M. Oppression. In Frye M. The Politics of Reality: Essays in Feminist Theory.: . Crossing Press; 1983. p. 1-16.

46 Saleebey D, Ski Hunter M. The power of situations: an approach to understanding . powerlessness and oppression. Journal of Sociology \& Social Welfare. 1980; 7: p. $177-187$.

47 Malterud K, Taksdal A. Shared spaces for reflection: Approaching medically . unexplained disorders. Junctures: The Journal for Thematic Dialogue. 2011; 9: p. 2738.

48 Kidd I. Illness, implicit bias, and intersectionality. [Online].; 2015. Available from: .https://www.academia.edu/5606598/Illness_Implicit_Bias_and_Intersectionality.

49 Ofri D. New York Times. [Online].; 2012. Available from: . http://well.blogs.nytimes.com/2012/11/15/when-the-patient-is-noncompliant.

50 Eriksen TE, Kirkengen AL, Vetlesen AJ. The Medically Unexplained revisited. . Medicine, Health Care and Philosophy. 2012; 16(3): p. 587-600.

51 Greco M. The classification and nomenclature of 'Medically Unexplained . Symptoms': conflict, performativity and critique. Social Science \& Medicine. 2012; 75(12): p. 2362-2369. 
52 Nettleton S. 'I just want permission to be ill': towards a sociology of Medically . Unexplained Symptoms. Social Science \& Medicine. 2006; 62(5): p. 1167-1178.

53 Rosenhan DL. On being sane in insane places. Science. 1973; 179(4070): p. 250.258 .

54 Gask L, Dowrick C, Salmon P, Peters S, Morriss R. Reattribution reconsidered: . narrative review and reflections on an educational intervention for Medically Unexplained Symptoms in primary care settings. Journal of Psychosomatic Research. 2011; 71(5): p. 325-334.

55 Lamberts R. A letter to patients with chronic disease. [Online].; 2010. Available . from: $\quad$ http://more-distractible.org/2010/07/14/a-letter-to-patients-with-chronicdisease.

56 Katz J. Epilogue: physician-patient encounters on a darkling plain. Western New . England Law Review. 1987; 9: p. 207-226.

57 Maguire P. Barriers to psychological care of the dying. British Medical Journal . (Clinical Research Ed.). 1985; 291: p. 1711-1713.

58 Åsbring P, Närvänen AL. Ideal versus reality: physicians' perspectives on patients . with chronic fatigue syndrome (CFS) and fibromyalgia. Social Science \& Medicine. 2003; 57: p. 711-720.

59 Anderson RM, Funnell MM. Patient empowerment: reflections on the challenge of . fostering the adoption of a new paradigm. Patient Education and Counseling. 2005; 57(2): p. $153-157$.

60 Blakeman T, Macdonald W, Bower P, Gately C, Chew-Graham C. A qualitative . study of GPs' attitudes to self-management of chronic disease. British Journal of General Practice. 2006; 56(527): p. 407-414.

61 Salmon P, Hall GM. Patient empowerment and control: a psychological discourse in . the service of medicine. Social Science \& Medicine. 2003; 57(10): p. 1969-1980.

62 Savino A, Fordtran J. Factitious disease: clinical lessons from case studies at Baylor . University Medical Center. Proceedings (Baylor University Medical Center). 2006; 19: p. 195-208. 
63 Anonymous. BMJ Blogs. [Online].; 2015. Available from: . http://blogs.bmj.com/bmj/2015/09/03/a-patients-perspective-dancing-the-dance/.

64 Lazare A. Shame and humiliation in the medical encounter. Archives of Internal . Medicine. 1987; 147: p. 1653-1658.

65 Malterud K. Humiliation instead of care? Lancet. 2005; 366(9488): p. 785-786.

66 Malterud K, Thesen J. When the helper humiliates the patient: A qualitative study . about unintended intimidations. Scandinavian Journal of Public Health. 2008; 36: p. 92-98.

67 Dickson A, Knussen C, Flowers P. Stigma and the delegitimation experience: An . interpretative phenomenological analysis of people living with chronic fatigue syndrome. Psychology \& Health. 2007; 22(7): p. 851-867.

68 Galasiński D. Medical Status of the Narrative. [Online].; 2016. Available from: . http://dariuszgalasinski.com/2016/12/14/medical-status-of-the-narrative.

69 Galasiński D. Language Matters: a Linguist's View on Medicine. Sexually . Transmitted Infections. 2017; 93(7): p. 456-457.

70 Wardrope A. Medicalization and epistemic injustice. Medicine, Health Care and . Philosophy. 2015; 18(3): p. 341-352.

71 Werner A, Isaksen LW, Malterud K. "I am not the kind of woman who complains of everything": Illness stories on self and shame in women with chronic pain. Social Science \& Medicine. 2004; 59: p. 1035-1045.

72 Anderson ES. Epistemic justice as a virtue of social institutions. Social . Epistemology. 2012; 26(2): p. 163-173.

73 Bohman J. Domination, epistemic injustice and republican epistemology. Social . Epistemology. 2012; 26(2): p. 175-187.

74 Carel H, Györffy G. Seen but not heard: children and epistemic injustice. Lancet. . 2014; 384(9950): p. 1256-1257. 
75 Dohmen J. 'A little of her language': epistemic injustice and mental disability. Res . Philosophica. 2016; 93(4): p. 669-691.

76 Lakeman R. Epistemic injustice and the mental health service user. International . Journal of Mental Health Nursing. 2010; 19(3): p. 151-153.

77 Sanati A, Kyratsous M. Epistemic injustice in assessment of delusions. Journal of . Evaluation in Clinical Practice. 2015; 21(3): p. 479-485.

78 Launer J. Heart failure - or a failure of imagination? Postgraduate Medical Journal. . 2005; 93(1101): p. 439-440.

79 Davis NA. Invisible disability. Ethics. 2005; 116(1): p. 153-213.

80 Ekstrom L. Liars, medicine, and compassion. Journal of Medicine and Philosophy. . 2012; 37: p. 159-180.

81 Holm S. What is wrong with compliance? Journal of Medical Ethics. 1993; 19: p. .108-110.

82 Ware N. Suffering and the social construction of illness: the delegitimation of illness . experience in chronic fatigue syndrome. Medical Anthropology Quarterly. 1992; 6: p. $347-361$.

83 Jutel A. Medically Unexplained Symptoms and the disease label. Social Theory \& . Health. 2010; 8(3): p. 229-245.

84 Thomas L. Are your patient's Medically Unexplained Symptoms really 'all in her . head'? Medical Hypotheses. ; 78(4): p. 542-547.

85 Blease C, Carel H, Geraghty K. Epistemic injustice in healthcare encounters: . evidence from chronic fatigue syndrome. Journal of Medical Ethics. 2017; 43: p. 549-557.

86 Freud S. A difficulty in the path of psycho-analysis (1917). In The Standard Edition . of the Complete Psychological Works of Sigmund Freud, trans. James Strachey, with Anna Freud, volume 17. London: Hogarth Press; 1968. p. 140-143. 


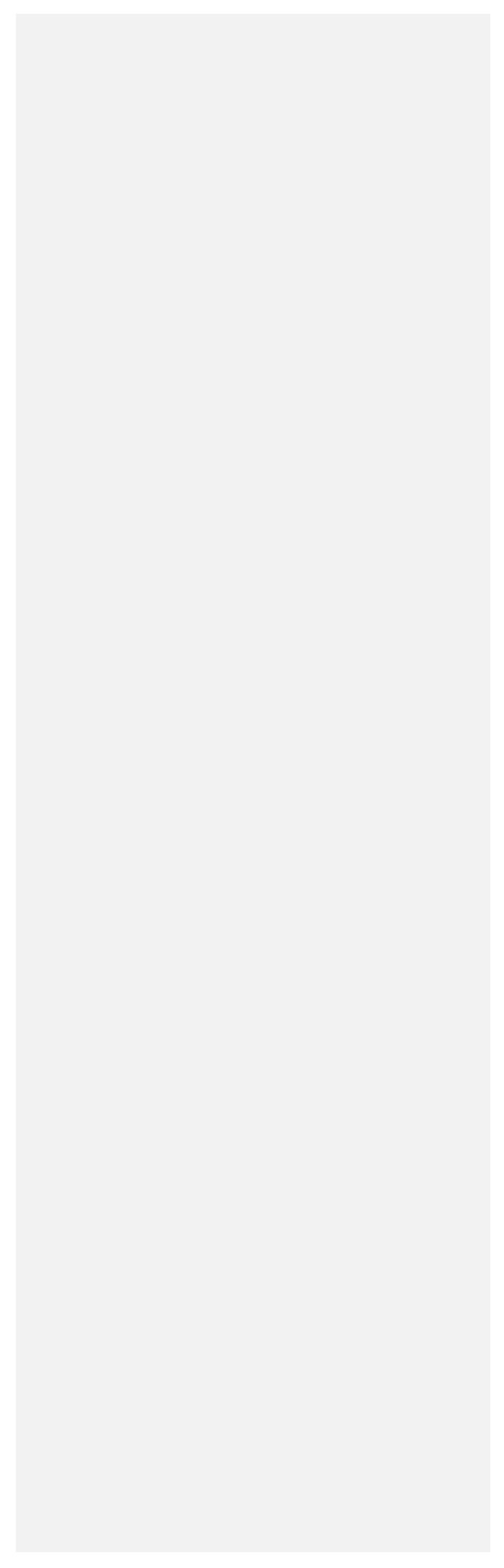

